\title{
Three-part humeral head fractures treated with a definite construct of blocked threaded wires: finite element and parametric optimization analysis
}

\author{
Stefano Gumina, MD, PhD ${ }^{\mathrm{a}}$, Vittorio Candela, $\mathrm{MD}^{\mathrm{a}, *}$, Arianna Cacciarelli, $\mathrm{BS}^{\mathrm{b}}$, \\ Eleonora Iannuzzi, BS ${ }^{\mathrm{b}}$, Giovanni Formica, $\mathrm{PhD}^{\mathrm{c}}$, Walter Lacarbonara, $\mathrm{PhD}^{\mathrm{a}}$ \\ ${ }^{a}$ Department of Anatomical, Histological, Forensic Medicine and Orthopaedics Sciences, Sapienza University of Rome, Istituto Clinico Ortopedico \\ Traumatologico (ICOT), Latina, Italy \\ ${ }^{\mathrm{b}}$ Department of Structural Engineering, Sapienza University of Rome, Rome, Italy \\ ${ }^{\mathrm{c}}$ Department of Architecture, Roma Tre University, Rome, Italy
}

\section{A R T I C L E I N F O}

\section{Keywords:}

Proximal humerus fracture three-part humeral head fracture external fixator

blocked threaded wires

biomechanical evaluation of pinning technique

percutaneous pinning technique

gold standard for proximal humerus

fracture

Level of evidence: Basic Science Study; Computer Modeling
Background: Mini open reduction and percutaneous fixation of three-part humeral head fracture with blocked threaded wires has demonstrated functional results similar to locking plates or intramedullary nails but with significantly lower major complication rate. In the context of three-part humeral head fractures, we performed a parametric optimization through a finite element analysis of a recently published construct to verify if the encouraging clinical results can be supported by a more rigorous investigation from a mechanical viewpoint.

Materials and Methods: The 2-dimensional geometry of a three-part proximal humerus fracture synthetized with a system of blocked threaded wires was created. Tension/bending/shear and compression load tests were simulated. A parametric optimization analysis was performed considering four design parameters (height of wire couples; wire material; interdistance between two wires). Eighteen simulations were carried out. Additional analyses were performed also considering a varying diameter of the external rod.

Results: Four points where the largest gap occurs and three points associated with the highest stress concentration were considered. As per the tension/bending/shear loading, a slight gap increase was observed in two different points $(8.494 \mu \mathrm{m} ; 7.540 \mu \mathrm{m})$, while a slight decrease was detected along the greater tuberosity fracture line $(1.445 \mu \mathrm{m})$. The maximum von Mises stress up to $64.4 \mathrm{MPa}$ was achieved in the humeral head. As per the compression loading, the gap increased along the greater tuberosity fracture line $(1.445 \mu \mathrm{m} ; 7.545 \mu \mathrm{m})$; the maximum von Mises stress attains the value of $64.42 \mathrm{MPa}$. The smallest gap distance $(15.37 \mu \mathrm{m})$ and the lowest von Mises stress (51.51 MPa) were obtained in two different alternative constructs. The diameter of the external rod had no significant effect.

Conclusions: The studied construct is biomechanically valid; it only allows micromovements (onethousandth of the characteristic humerus size) that are not able to cause humeral head rotation and translation. Furthermore, the construct generates acceptable pressure stresses on sensible areas of the fractured humeral head. Compared to the original construct, we propose to space the pair of horizontal wires for the great tuberosity by at least $1 \mathrm{~cm}$.

(c) 2021 The Authors. Published by Elsevier Inc. on behalf of American Shoulder and Elbow Surgeons. This is an open access article under the CC BY-NC-ND license (http://creativecommons.org/licenses/bync-nd/4.0/)
Locking plates and intramedullary nail are the most commonly used devices for the fixation of three-part humeral head fractures, each of which should be used depending on the characteristics of

Institutional review board approval was not required for this basic science study. *Corresponding author: Vittorio Candela, MD, Department of Anatomy, Histology, Legal Medicine and Orthopedics, University of Rome, Piazzale Aldo Moro 5, 00185, Rome, Italy.

E-mail address: Vittorio.candela@yahoo.it (V. Candela). the fracture (integrity of the medial hinge and of the lateral and medial columns), patient age, and osteoporosis degree. ${ }^{5,11,13}$ Literature data indicate that the use of these fixation systems involves a percentage of major complications (avascular necrosis, nonunion, and sintering) that ranges from $9 \%$ to $40 \%{ }^{4,6,11,15,18}$ Recently, fixation of complex three-part humeral head fractures through a system of blocked threaded wires (BTWs) and a mini $(2.5 \mathrm{~cm})$ deltopectoral approach has been reported to lead to similar clinical and radiological outcomes with respect to locking plate and nail, ${ }^{7}$ 


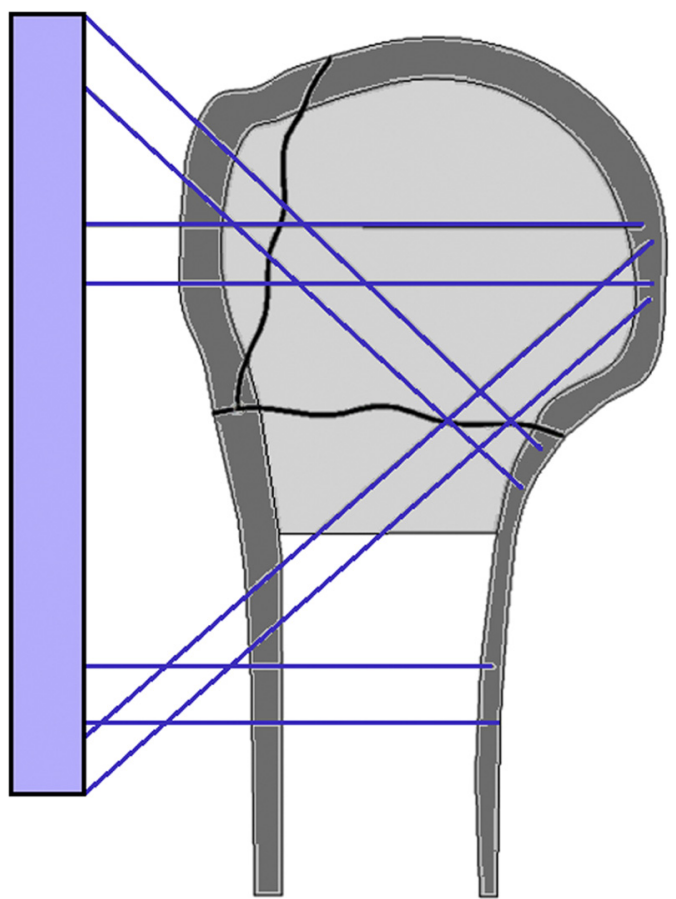

Figure 1 Geometry of the three part proximal humerus fracture synthetized by the definite construct of blocked threaded wires. The cortical (in dark gray) and the trabecular (in light gray) subdomains can be recognized.

but major complication rate was quite lower. The maintenance of periosteal and fracture hematoma, together with the preservation of proximal humeral bone stock (with no multiple perforations of the humeral head) and of the medullary tissue could explain the lower rate of major complications. Rate of superficial and deep infections was also lower, probably owing to the reduced extent of the surgical approach and to the shorter operating time. In addition, it is plausible that the early removal of the fixation device might facilitate bone healing.

The proposed fixation system creates a BTW construct $^{2}$ able to limit translation and collapse of the humeral head in the postoperative period. However, no biomechanical investigation has ever validated this construct.

We performed a finite element incremental analysis of failure mechanisms accounting for the evolution of gap distance and stress at the bone-implant interface of this BTW construct for three-part proximal humeral fractures to validate the system reliability and to evaluate the existence of better performing configurations of BTW.

\section{Materials and methods}

COMSOL Multiphysics (COMSOL Multiphysics v.5.4., COMSOL $\mathrm{AB}$, Stockholm, Sweden) was chosen as the finite element solver.

The geometry of the fractured humeral head was generated via a 3-dimensional computer aided design solid modeling software called Solid Edge (Solid Edge, Siemens PLM Software). A two-dimensional (2D) model, generated from the three-part (Hertel $7^{8}$ ) proximal humeral fracture (Fig. 1) was created for this type of investigation.

Figure $2 A$ shows the adopted mesh for the finite element analysis with the adopted loading patterns. The different sizes of the meshes were owing to the presence of the contact pair at the interface between the subdomains along the fracture lines.

The threaded wires were represented by one-dimensional beam elements (elastically defined as per axial, bending, and torsional stiffnesses) fixed to the external rod modeled as a carbon-fiber composite 2D plate. Continuity was enforced between the bone and the inserted wires by means of the identity boundary pair which, by default, makes the fields across two connected boundaries continuous. The bone tissue was modeled as a linearly elastic, isotropic material, with distinct properties for the cortical and trabecular parts as shown in Table I. ${ }^{12,16}$

The threaded wires were modeled as metallic alloy beams, made either of stainless steel (Young's modulus of $200 \mathrm{GPa}$, yield stress of $215 \mathrm{MPa}$ ) or Titanium (Young's modulus of $115 \mathrm{GPa}$, yield stress of $140 \mathrm{MPa}$ ) or Titanium Ti-6Al-4V (Young's modulus of $113.9 \mathrm{GPa}$, a

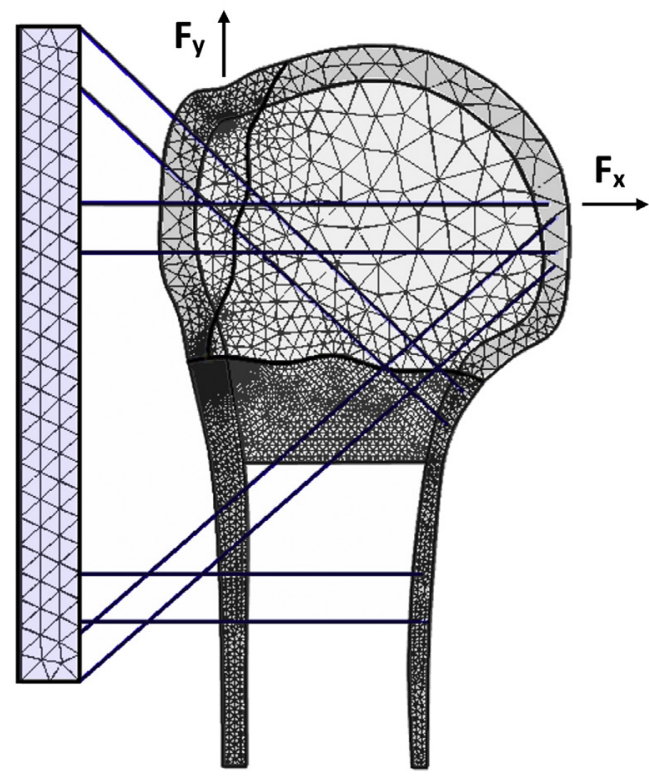

b

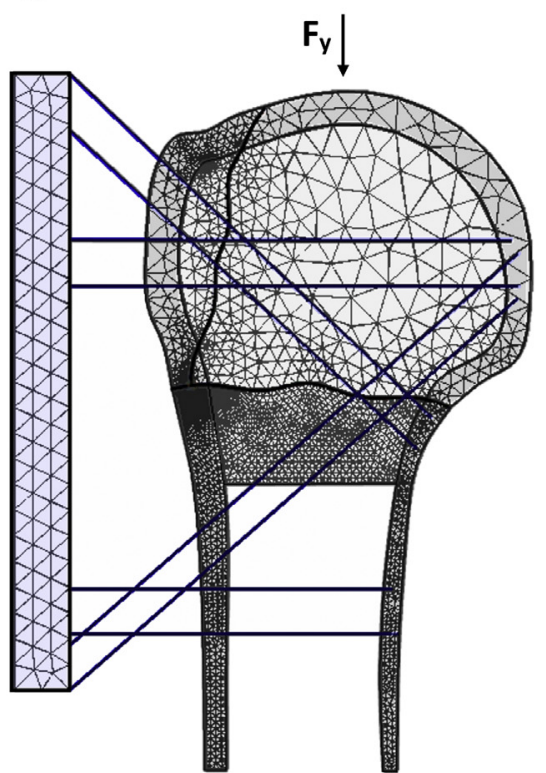

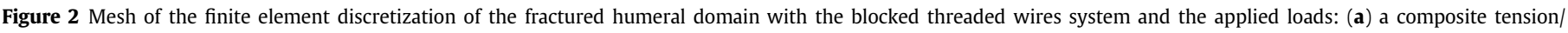
bending/shear loading and (b) a compression loading. 
Table I

Mechanical properties of the bone and the blocked threaded wires system.

\begin{tabular}{lccl}
\hline Bone & $\mathrm{E}(\mathrm{GPa})$ & $\rho\left(\mathrm{kg} / \mathrm{m}^{3}\right)$ & $v$ \\
\hline Cortical bone & 17.2 & 1850 & 0.300 \\
Trabecular bone & 1.2 & 500 & 0.300 \\
Fixation system & & & \\
$\quad$ Composite rod & 270.0 & 1900 & 0.300 \\
Stainless steel wires & 200.0 & 8000 & 0.290 \\
Titanium wires & 115.0 & 4500 & 0.340 \\
Ti-6Al-4V wires & 113.9 & 4430 & 0.342 \\
\hline
\end{tabular}

E is Young's modulus, $\rho$ is the mass density, and $v$ is Poisson's ratio.

Table II

Factors and their alternate levels.

\begin{tabular}{llll}
\hline Factors & Level 1 & Level 2 & Level 3 \\
\hline Wires AB (height) & $0.3210 \mathrm{~m}$ & $0.3250 \mathrm{~m}$ & $0.3285 \mathrm{~m}$ \\
Wires EF (height) & $0.2140 \mathrm{~m}$ & $0.2240 \mathrm{~m}$ & $0.2290 \mathrm{~m}$ \\
Material & Titanium & Ti-6Al-4V & Stainless steel \\
CD interdistance & $8 \mathrm{~mm}$ & $10 \mathrm{~mm}$ & $13 \mathrm{~mm}$
\end{tabular}

The heights reported refer to the COMSOL reference system and correspond to the average mean distance between the considered couple of wires (as a reference: the height of the lowest point of the rod is equal to $0.21 \mathrm{~m}$ (lev.1), $0.22 \mathrm{~m}$ (lev.2), $0.225 \mathrm{~m}$ (lev.3).

yield stress of $880 \mathrm{MPa}$ ). The material of the lightweight external rod was modeled as a carbon fiber composite plate.

Two loading cases were reported to simulate the behavior of a displaced Hertel 7 fracture $^{8}$ : (1) a composite tension/bending/shear loading due to a pair of eccentric tensile loads and (2) a compression loading (Fig. 2). The first loading pattern consists of two tensile point loads applied to the stabilized fractured humerus, namely, $\mathrm{F}_{x}$ on the right part of the humerus head and $\mathrm{F}_{y}$ on the greater tuberosity. This complex loading pattern aims to combine axial tensile load and bending so as to simulate one of worst loading scenarios. Other elementary loading cases such as pure compression, pure bending, or shear or torsion were not considered owing to either the presumed lower impact on the stability or the chosen 2D context. A parametric sweep was performed to path follow the change of the mechanical response upon variation of the forces in a suitable range, namely, $\mathrm{F}_{x}$ from $10 \mathrm{~N}$ to $500 \mathrm{~N}, \mathrm{~F}_{y}$ from $5 \mathrm{~N}$ to $250 \mathrm{~N}$. These forces were applied in 10 load steps with a unique load multiplier $\lambda$ (ie, the forces grow at the same rate) as per (Fx, Fy) $=\lambda$ $(2,1)$ with $\lambda=(5.0,32.2,59.4,86.6,113.8,141.1,168.3,195.5,222.7$,
250.0). The maximum load magnitude was chosen in a plausible load range such that the associated stresses were significantly large (worst loading scenario) but not so large as to approach the bone failure stresses.

A compression loading case with the load atop the humeral head pointing in the vertical downward direction (Fig. 2B) was also investigated. A parametric sweep was run in the range from $10 \mathrm{~N}$ to $500 \mathrm{~N}$.

\section{Parametric analysis}

Sensitivity of the system parameters on the response of the stabilized fractured bone was successfully investigated using the Taguchi and analysis of variance methods. ${ }^{10}$ Four design parameters, each represented by three values, were considered (Table II).

Through the use of the L9 Taguchi orthogonal array, only 9 simulations sufficed. In addition to the 9 minimal simulations, further configurations were tested to obtain a more exhaustive exploration of the parameters space. The explored simulations are presented in Table III. The geometry of the construct is modified by adjusting the heights of the wires $\mathrm{AB}$ and $\mathrm{EF}$, and the distance between wires $C$ and $D$. The distance between $A B$ and $E F$ wires was set to $8 \mathrm{~mm}$ and kept unchanged (Fig. 3). Moreover, three different materials for the fixation system were used.

The maximum distance between wires was set at $12 \mathrm{~mm}$ because it is the maximum distance that allows the two wires to be tightened with a single wire clamp. The height of the couple of diaphyseal threaded wires was not investigated.

The analysis of variance was used to predict the sensitivity of the response with respect to the design parameters, thus providing a quantitative measure of how various factors affect the performance of the bone/construct system. The selected outputs were the gap distance measured as the sum of the distances observed in the fracture openings and the maximum von Mises stress in the bone. A second analysis of variance was performed considering another design parameter, the diameter of the external $\operatorname{rod}(8 \mathrm{~mm}, 10 \mathrm{~mm}$, and $12 \mathrm{~mm}$ ).

\section{Results}

\section{Finite element analysis}

Four control points along the fracture lines were detected as the points where the largest through-the-fracture gaps occurred, and

Table III

Simulation cases representing various possible geometries and materials of the blocked threaded wires fixation system.

\begin{tabular}{|c|c|c|c|c|}
\hline Simulation \# & Wires $A B$ height $(m)$ & Wires EF height (m) & Material & $\mathrm{CD}$ distance $(\mathrm{mm})$ \\
\hline 1 & 0.3250 & 0.2140 & Titanium & 13 \\
\hline 2 & 0.3210 & 0.2140 & Ti-6Al-4V & 10 \\
\hline 3 & 0.3250 & 0.2240 & Stainless steel & 10 \\
\hline 4 & 0.3210 & 0.2290 & Stainless steel & 13 \\
\hline 5 & 0.3210 & 0.2240 & Titanium & 8 \\
\hline 6 & 0.3285 & 0.2240 & Ti-6Al-4V & 13 \\
\hline 7 & 0.3285 & 0.2140 & Stainless steel & 8 \\
\hline 8 & 0.3285 & 0.2290 & Titanium & 10 \\
\hline 9 & 0.3250 & 0.2290 & Ti-6Al-4V & 8 \\
\hline 10 & 0.3250 & 0.2240 & Titanium & 8 \\
\hline 11 & 0.3250 & 0.2140 & Titanium & 8 \\
\hline 12 & 0.3210 & 0.2140 & Titanium & 8 \\
\hline 13 & 0.3250 & 0.2240 & Stainless steel & 8 \\
\hline 14 & 0.3250 & 0.2140 & Stainless steel & 8 \\
\hline 15 & 0.3210 & 0.2240 & Stainless steel & 8 \\
\hline 16 & 0.3210 & 0.2140 & Stainless steel & 8 \\
\hline 17 & 0.3250 & 0.2240 & Titanium & 13 \\
\hline 18 & 0.3285 & 0.2240 & Ti-6Al-4V & 10 \\
\hline
\end{tabular}


a

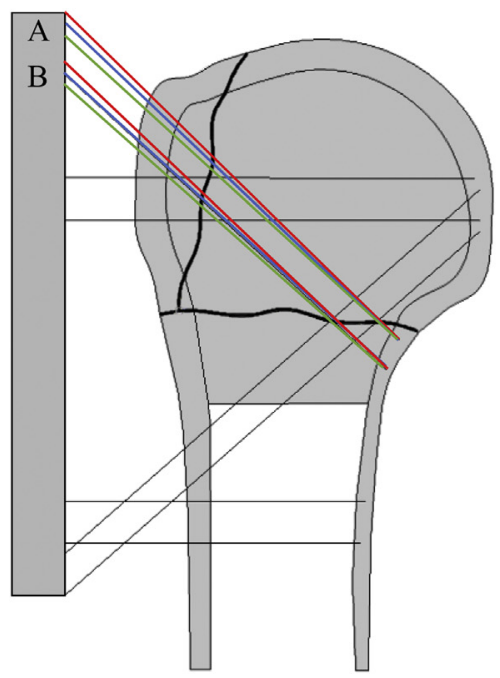

b

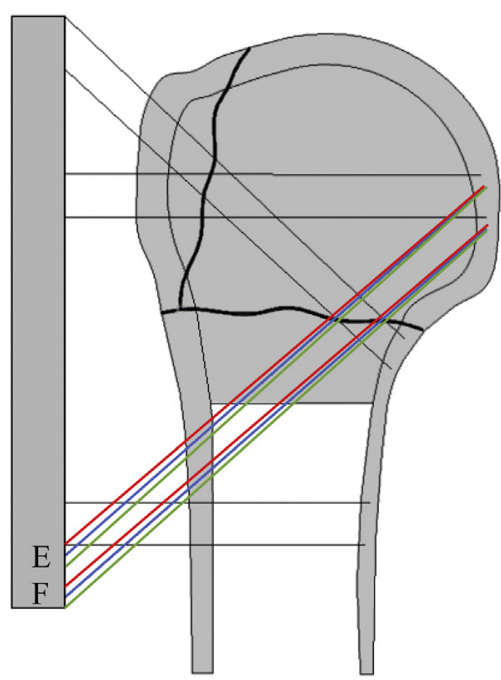

C

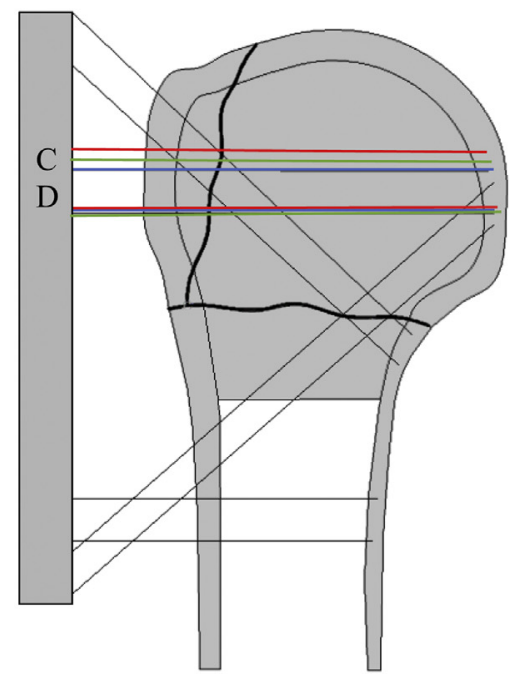

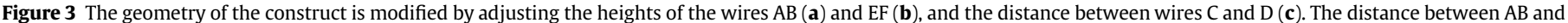
EF wires was set to $8 \mathrm{~mm}$ and kept unchanged.

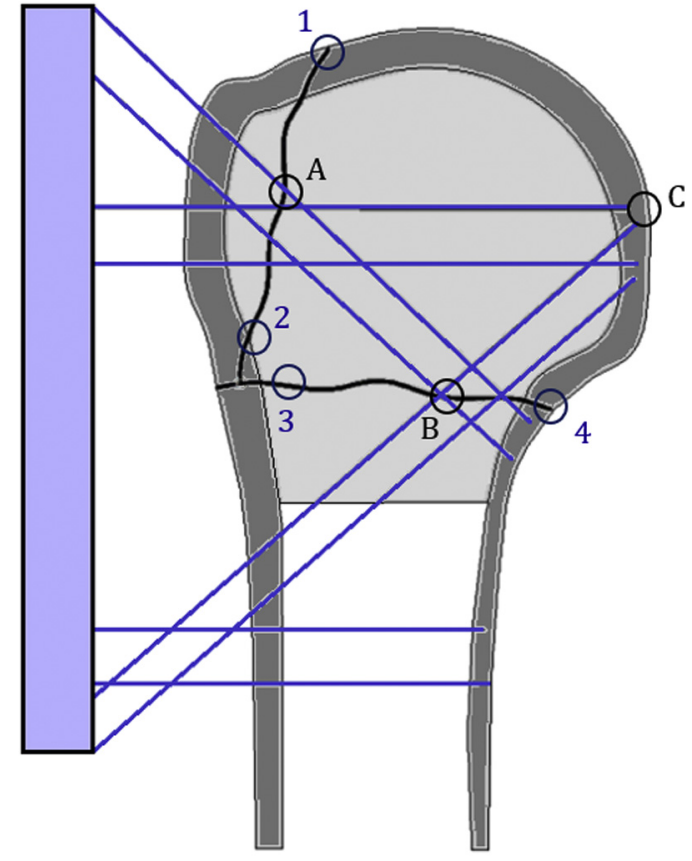

Figure 4 Four control points along the fracture lines were detected as the points where the largest through-the-fracture gaps occurred (1,2,3, and 4$)$ and three points were found to be associated with the highest stress concentrations (A, B, and $C)$.

three points were found to be associated with the highest stress concentrations (Fig. 4).

The stress map for the first loading step was shown in Figure 5 together with the displaced configuration; the right and upper parts of the bone undergo a rotary motion about point 4 . A slight gap increase is observed at point 1 (from $8.441 \mu \mathrm{m}$ to $8.494 \mu \mathrm{m}$ ) and at point 3 (from $7.534 \mu \mathrm{m}$ to $7.540 \mu \mathrm{m}$ ), while a slight decrease occurs at point 2 (from $1.464 \mu \mathrm{m}$ to $1.445 \mu \mathrm{m}$ ). The maximum von Mises stress up to $64.4 \mathrm{MPa}$ is achieved at point A under the first a

1: $F x=10, F y=5$ Surface: von Mises stress $\left(N / m^{2}\right)$
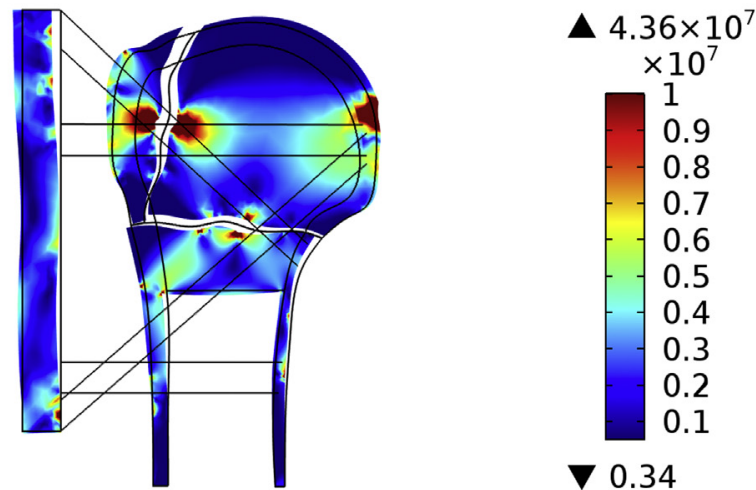

b

\section{1: $F x=10, F y=5$ Contour: von Mises stress $\left(\mathrm{N} / \mathrm{m}^{2}\right)$}
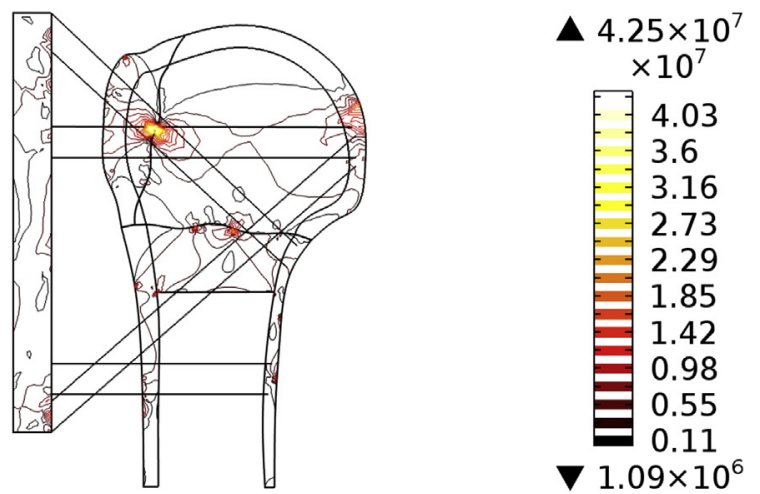

Figure 5 Von Mises stress (in Pa) and deformed image for the first load step (a); von Mises stress contour plot under the tension/bending/shear load (b). 

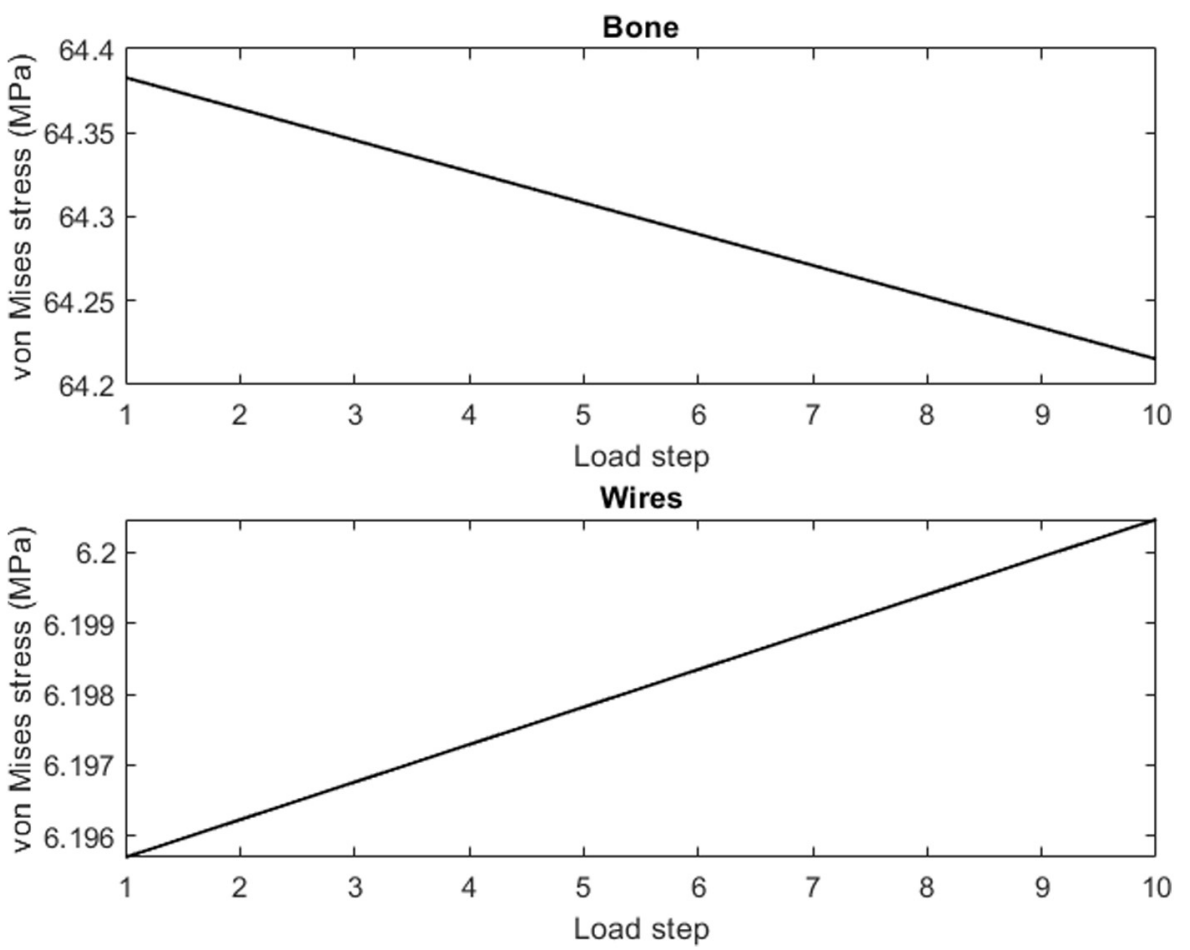

Figure 6 Evolution of the maximum von Mises stress on the bone and metallic wires with the load step.

load step. The other two stress concentrations at $\mathrm{B}$ and $\mathrm{C}$ have lower values (about $39 \mathrm{MPa}$ and $22 \mathrm{MPa}$, respectively). By considering a bone yield strength ranging from $80 \mathrm{MPa}$ to $110 \mathrm{MPa}$, the computed stresses are consistent with the assumed linearly elastic analysis.

Figure 6 shows the von Mises stress change in both the bone and the wires with the increasing applied loads.

The stress map for the compression load is shown in Figure 7, superimposed on the deformed configuration. The gap is substantially stable at point 1 , while slight increases are observed at point 2 (from $1.46448 \mu \mathrm{m}$ to $1.445 \mu \mathrm{m}$ ) and at point 3 (from $7.5337 \mu \mathrm{m}$ to $7.54045 \mu \mathrm{m}$ ), respectively. On the other hand, the maximum von Mises stress for the last loading step $(F=-500 \mathrm{~N})$ attains the value of $64.42 \mathrm{MPa}$.

\section{Parametric analysis}

The contribution percentage of each design parameter on the outputs is shown in Figure 8.

Lower fracture openings were also reported when the $C D$ interwire distance is 10 or $13 \mathrm{~mm}$ (along the y-axis), although this design yields higher von Mises stresses. Figure 9 shows the influence of the wires distance on the von Mises stress and gap distance.

Maximum von Mises stress and gap distance for all simulation cases are shown in Figure 10. The minimum gap distance of $15.37 \mu \mathrm{m}$ was obtained with the third combination, while the lowest von Mises stress of $51.51 \mathrm{MPa}$ occurred with the 12th combination.

Finally, the sensitivity with respect to the three different used wires is shown in Figure 11. For less-compliant materials (Stainless steel) with higher Young's modulus, the gap distance decreases and the maximum von Mises stress increases.

The geometries which guarantee minimum gap distance are those making use of stainless steel for the wires. On the other hand, the absolute minimum stress is obtained with Titanium in simulation case \#12 (51.51 MPa) at the expense of a larger gap (20.43 $\mathrm{mm})$.

In accordance with the diameter of the external rod, no effect on the design performance was detected. In fact, analysis of variance shows that the percentage contribution of the diameter of the rod is only $2.47 \%$.

\section{Discussion}

Locking plates and intramedullary nailing represent the gold standard in the treatment of active patients with three- and fourpart stable fractures of the proximal humerus. Boudard et $\mathrm{al}^{1}$ observed no differences in terms of final functional assessment, between locking plate and intramedullary nailing. In a recent comparative, multicenter, retrospective study, ${ }^{5}$ it was observed that if the medial hinge is preserved, locking plate is recommended; in other cases, both devices can be used. In 2019, Lorenz et $\mathrm{al}^{13}$ stated that just hundred half of the patients with three-four part fractures treated with these devices suffered at least one complication (screw perforation; nonunion and avascular necrosis). Recently, Gumina et $\mathrm{al}^{7}$ proposed to fix a reduced (through a mini open delto-pectoral approach $-2 \mathrm{~cm}$ ) three-part humeral head fracture using, for 45 days, BTWs, percutaneously inserted in such a way as to always obtain the same isostatic construct. The authors obtained similar functional results obtainable with other fixation systems but drastically reducing the percentage of major complications. This promising fixation obtained using always in the same manner 8 threaded steel wires, 4 wire locking clamps, 4 clamps, and 1 carbon fiber bar (Galaxy Shoulder Fixation - Orthofix) has not yet been biomechanically tested and validated.

We performed a finite element and parametric optimization analysis of this apparently isostatic construct simulating a three- 
a

$$
\mathrm{Fy}(1)=-500 \text { Surface: von Mises stress }\left(\mathrm{N} / \mathrm{m}^{2}\right)
$$
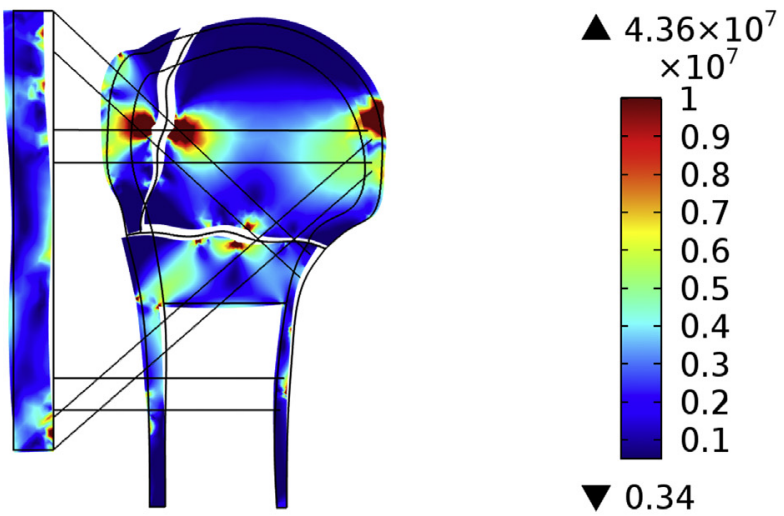

b

$$
\mathrm{Fy}(1)=-500 \text { Contour: Total displacement }(\mathrm{m})
$$
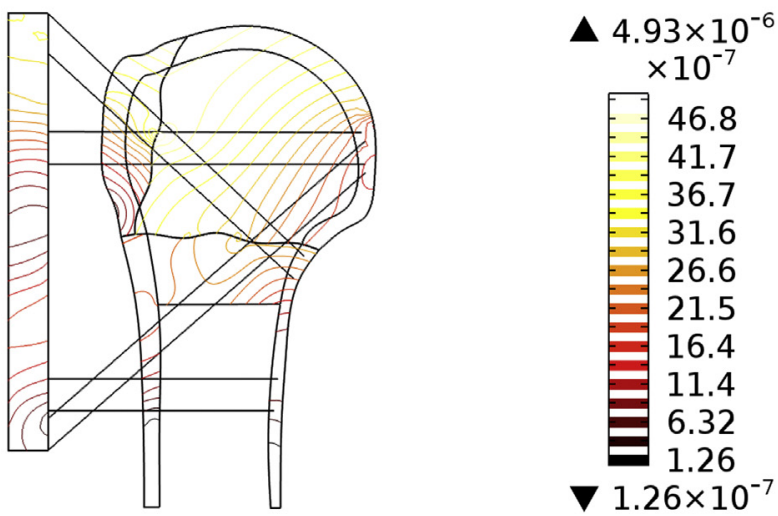

Figure 7 Von Mises stress (in Pa) and deformed image for the first load step (a); von Mises stress contour plot under the compression load (b).

part fracture to verify if also from a structural mechanics viewpoint the construct could explain the encouraging clinical results. Nonlinear finite element analysis is one of the viable numerical approaches to study the mechanics of a fractured humeral bone stabilized by an external fixation system. Given the complex geometrical domain with several subdomains and the inhomogeneity of the material properties, the finite element method allows to partition the various domains in smaller regions (ie, finite elements) whose geometry can be well adapted to describe the curved and fractal-like outer and inner boundaries (ie, fracture surfaces) or the interfaces between them. Other multibody dynamical modeling approaches to study the nonlinear response and vibrations of such complex nonlinear bone-fixation systems are possible $\mathrm{e}^{14,20}$; two loading scenarios (tension/bending/shear and compression forces) were set to simulate the displacement forces of the 3-part displaced proximal humeral fractures.

The studied construct turned out to be biomechanically valid because, upon applying a severe loading scenario, it only allows micromovements ranging from 1.5 to $8.4 \mu \mathrm{m}$. This order of magnitude is not able to determine translation or rotation of the humeral head and therefore does not cause fragment dislocations. Furthermore, the studied construct generates pressure stresses on the surgical neck (39 MPa), on the greater tuberosity-head fracture line (65 MPa) and close to the cephalic end of the distal proximal pins (E-F) (22 MPa), but they markedly differ (10 times below) from those which are able to cause bone pathologic changes, resorption, and nonhealing. ${ }^{3}$ Each screw of a locking plate also generates stresses lower than the bone tolerance limits, ${ }^{19}$ even lower than those generated by the E-F couple wires; however, locking plates usually need a considerable number of cephalic screws for obtaining a stable fixation; it follows that a large humeral head area is affected by this stress. In addition, the studied construct does not generate the stress caused by the locking plate at the bone-implant interface (150 MPa). ${ }^{19}$ Therefore, it is conceivable that the studied construct may favor fracture healing because it is not an absolute rigid system and because it does not cause high and widespread pressure stresses., 9,17

To evaluate possible fixation system improvement, we performed a parametric analysis and compared the studied construct with 18 possible combinations, keeping the pair of diaphyseal threads as a fixed parameter. The alternative $( \pm 3 \mathrm{~mm})$ insertion of the A-B and E-F wires does not significantly affect the interfragmentary mobility and pressure stresses on the bone. Whenever the greater tuberosity fragment is single and sufficiently large, the geometry can be optimized by setting the horizontal wires $\mathrm{C}$ and $\mathrm{D}$ at the distance of $12 \mathrm{~mm}$ which is the maximum distance that allows the two wires to be tightened with a single wire clamp. (B) In this study, we carried out a simulation by providing for the use of 2.5-mm-diameter steel wires. The analysis showed that the possible use of titanium wires would mitigate the pressure stresses on the three areas described previously but would increase the interfragmentary micromovements. However, even these micromovements generated by the use of titanium do not cause rotations or translations of the humeral head. Therefore, steel and titanium can be indiscriminately used depending on the patient's material tolerance. Our study also highlighted that if we aimed to obtain similar results by making use of steel and titanium wires, we would have to increase the diameter of the titanium wires from $2.5 \mathrm{~mm}$ to an impractical diameter of $12 \mathrm{~mm}$. Finally, a carbon fiber bar of greater diameter, up to twice the initially tested one, did not exhibit a significant effect on the design performance.

This study has limitations that need to be mentioned. This is a 2D analysis; the threaded wires were considered as parallel and not divergent from each other. The additional components (wire clamps and clamps) that could play a role in the effectiveness of the construct were not considered.

Further studies will be needed to evaluate the construct in its three-dimensionality and to compare it to any other types of constructs such as plate or nail.

\section{Conclusions}

We observed that the studied construct, subject to a severe loading scenario, it only allows micromovements that are not able to cause fragment translation. Furthermore, the construct generates sustainable pressure stresses on sensible areas of the fractured humeral head. Therefore, it is conceivable that it does not adversely affect the fracture healing process since it is not an absolute rigid system and because it does not cause high and widespread pressure stresses. Compared with the original construct, a spacing of at least $1 \mathrm{~cm}$ of the horizontal pair of wires for the great tuberosity is recommended.

\section{Disclaimers:}

Funding: No funding was disclosed by the author(s). Conflicts of interest: The authors, their immediate families, and any research foundations with which they are affiliated have not 


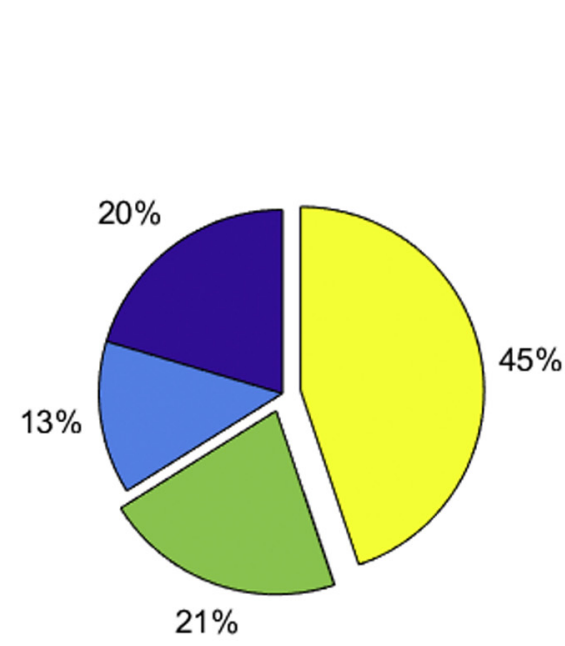

Percentage influence of parameters on the gap distance
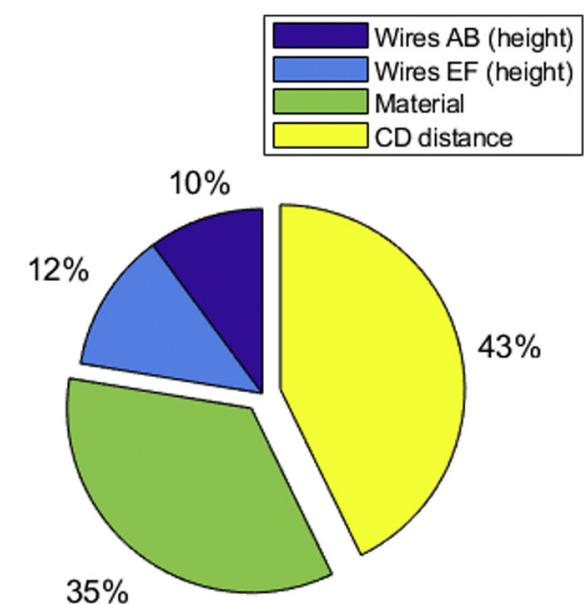

Percentage influence of parameters on the von Mises stress

Figure 8 Contribution percentage of each investigated design parameter.
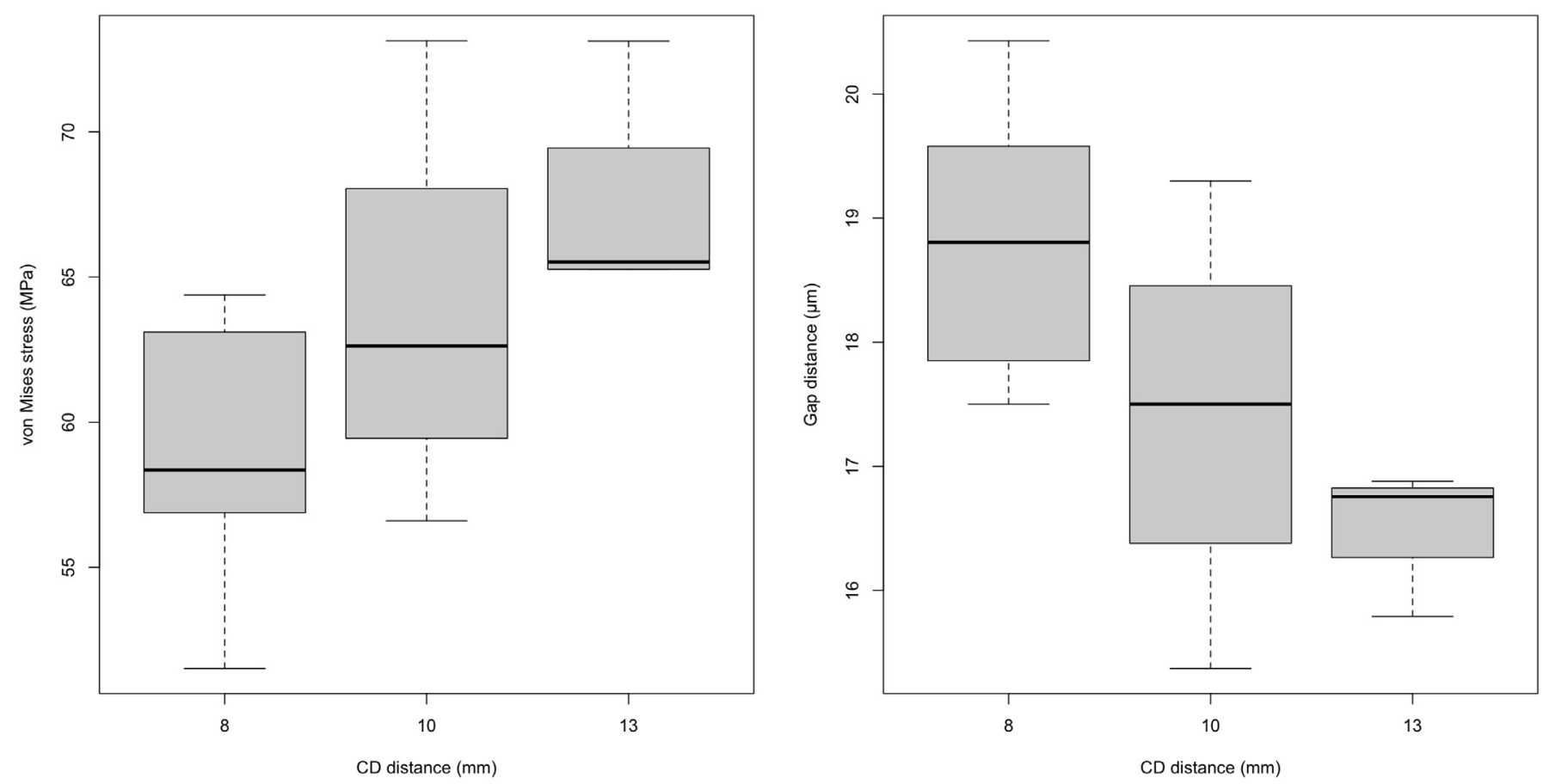

Figure 9 Effects of $\mathrm{CD}$ distance on maximum von Mises stress of the bone and gap distance. 
von Mises stress (Mpa) $\quad$ Gap distance $(\mu \mathrm{m})$

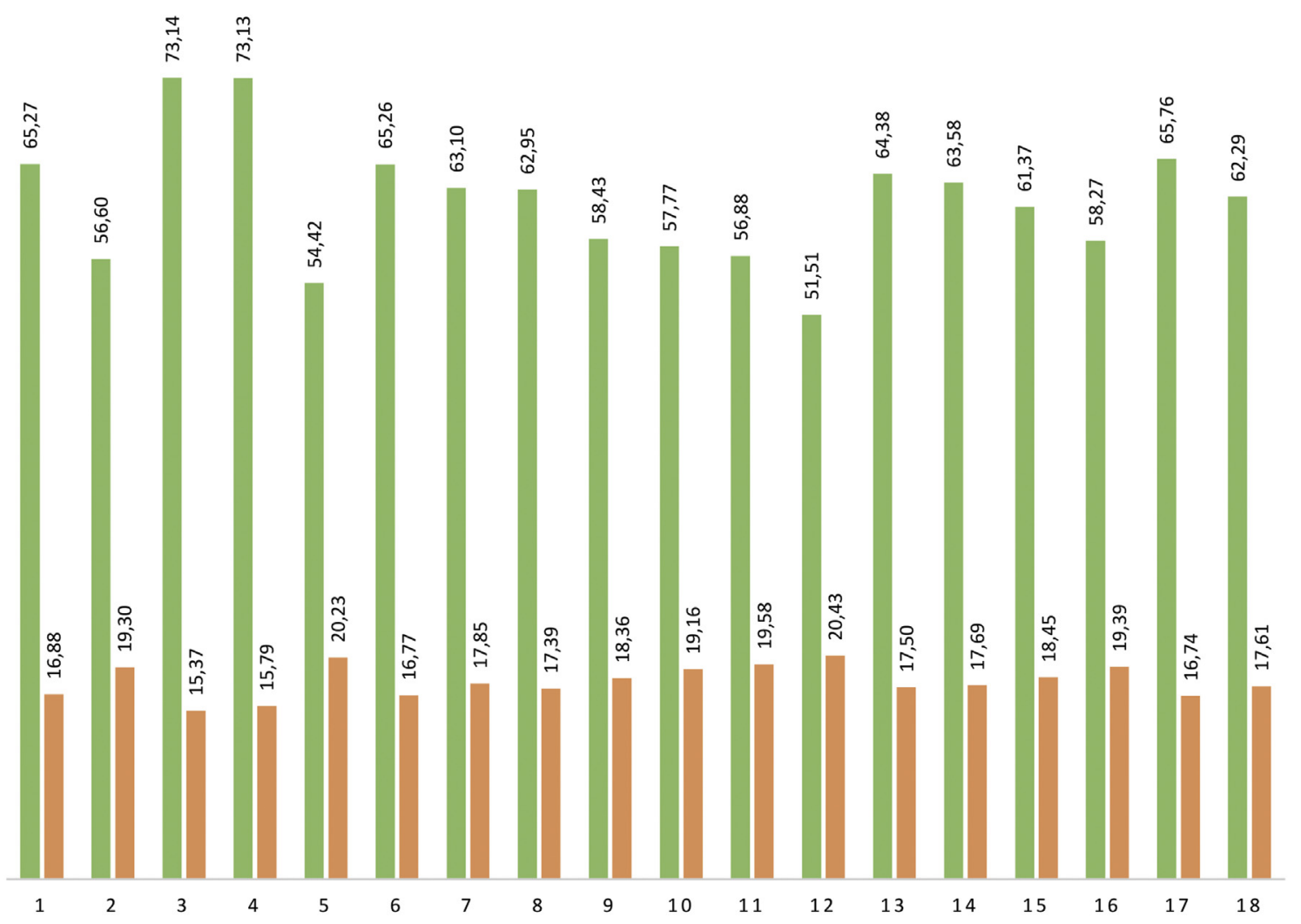

Figure 10 Maximum von Mises stress and gap distance in the 18 simulation cases.
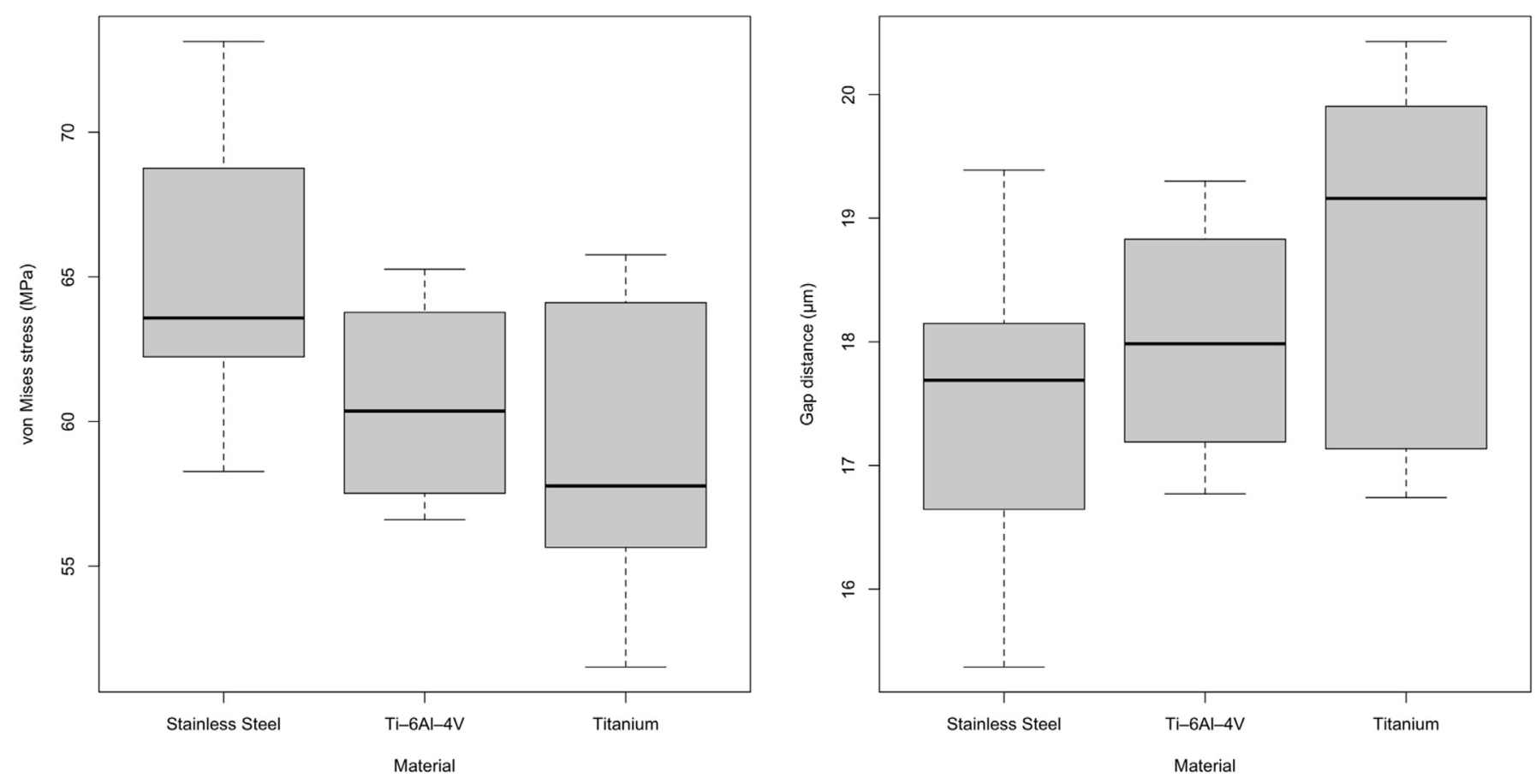

Figure 11 Effects of material on maximum von Mises stress of the bone and gap distance. 
received any financial payments or other benefits from any commercial entity related to the subject of this article.

\section{Acknowledgments}

WL gratefully acknowledges partial support by the Italian Ministry of Education, University and Scientific Research under PRIN Grant No. 201 and Sapienza University of Rome under Grant N. RG11916B8160BCCC.

\section{References}

1. Boudard G, Pomares G, Milin L, Lemonnier I, Coudane H, Mainard D, Delagoutte JP. Locking plate fixation versus antegrade nailing of 3- and 4-part proximal humerus fractures in patients without osteoporosis. Comparative retrospective study of 63 cases. Orthoptraumatol Surg Res 2014;100:917-24. https://doi.org/10.1016/j.otsr.2014.09.021.

2. Carbone S, Tangari M, Gumina S, Postacchini R, Campi A, Postacchini F. Percutaneous pinning of three- or four-part fractures of the proximal humerus in elderly patients in poor general condition: MIROS ${ }{ }$ versus traditional pinning. Int Orthop 2012;36:1267-73. https://doi.org/10.1007/s00264-0111474-5.

3. Claes L. Improvement of clinical fracture healing - what can be learned from mechano-biological research? J Biomech 2020;115:110148. https://doi.org/ 10.1016/j.jbiomech.2020.110148.

4. Faraj D, Kooistra BW, VdStappen WA, Werre AJ. Results of 131 consecutive operated patients with a displaced proximal humerus fracture: an analysis with more than two years follow-up. Eur J Orthop Surg Traumatol 2011;21:712. https://doi.org/10.1007/s00590-010-0655-z.

5. Gadea F, Favard L, Boileau P, Cuny C, d'Ollone T, Saragaglia D, Sirveaux F, SOFCOT. Fixation of 4-part fractures of the proximal humerus: can we identify radiological criteria that support locking plates or IM nailing? Comparative, retrospective study of 107 cases. Orthoptraumatol Surg Res 2016;102:963-70. https://doi.org/10.1016/j.otsr.2016.09.015.

6. Gumina S, Baudi P, Candela V, Campochiaro G. Hertel 7 fracture of the humeral head. Can two different fixation systems (Diphos/PHP) lead to different outcomes? A retrospective study. Injury 2016;47:S59-63. https://doi.org/10.1016/ j.injury.2016.07.051.

7. Gumina S, Candela V, Giannicola G, Orsina L, Passaretti D, Villani C. Complex humeral head fractures treated with blocked threaded wires: maintenance of the reduction and clinical results with two different fixation constructs. J Shoulder Elbow Surg 2019;28:36-41. https://doi.org/10.1016/j.jse.2018.06.034.
8. Hertel R, Hempfing A, Stiehler M, Leunig M. Predictors of humeral head ischemia after intracapsular fracture of the proximal humerus. J Shoulder Elbow Surg 2004;13:427-33. https://doi.org/10.1016/j.jse.2004.01.034.

9. Hulth A. Current concepts of fracture healing. Clin Orthop Relat Res 1989;249: 265-84.

10. Kolasangiani R, Mohandes Y. Bone fracture healing under external fixator: Investigating impacts of several design parameters using Taguchi and ANOVA Biocybernetics Biomed Eng 2020;40:1525-34. https://doi.org/10.1016/ j.bbe.2020.09.007.

11. Krappinger D, Bizzotto N, Riedmann S, Kammerlander C, Hengg C, Kralinger FS Predicting failure after surgical fixation of proximal humerus fractures. Injury 2011;42:1283-8. https://doi.org/10.1016/j.injury.2011.01.017.

12. Kruszewski A, Piszczatowski S, Piekarczyk P, Kwiatkowski K. Evaluation of stabilization of intra-articular fracture of distal humerus - finite element study. Acta Bioeng Biomech / Wroclaw Univ Technology 2020;22:153-63. https:/ doi.org/10.37190/ABB-01476-2019-03.

13. Lorenz G, Schönthaler W, Huf W, Komjati M, Fialka C, Boesmueller S Complication rate after operative treatment of three- and four-part fractures of the proximal humerus: locking plate osteosynthesis versus proximal humeral nail. Eur J Trauma Emerg Surg 2020;24. https://doi.org/10.1007/s00068-02001380-7.

14. Machado M, Flores P, Claro JCP, Ambrósio J, Silva M, Completo A, et al. Development of a planar multibody model of the human knee joint. Nonlinear Dyn 2010;60:459-78.

15. Majed A, Macleod I, Bull AM, Zyto K, Resch H, Hertel R, et al. Proximal humeral fracture classification systems revisited. J Shoulder Elbow Surg 2011;20:112532. https://doi.org/10.1016/j.jse.2011.01.020.

16. Morgan E, Barnes G, Einhorn T. The bone Organ system. Form and function Osteoporosis. 4th Edition 2013. p. 3-20. https://doi.org/10.1016/B978-0-12415853-5.0001-7.

17. Postacchini F, Gumina S, Perugia D, De Martino C. Early fracture callus in the diaphysis of human long bones. Histologic and ultrastructural study. Clin Orthoprelat Res 1995;310:218-28.

18. Südkamp N, Bayer J, Hepp P, Voigt C, Oestern $H$, Kääb $M$, Luo C, Plecko $M$ Wendt K, Köstler W, Konrad G. Open reduction and internal fixation of proximal humeral fractures with use of the locking proximal humerus plate. Results of a prospective, multicenter, observational study. J Bone Joint Surg Am 2009;91:1320-8. https://doi.org/10.2106/JBJS.H.00006.

19. Yang P, Zhang Y, Liu J, Xiao J, Ma LM, Zhu CR. Biomechanical effect of medial cortical support and medial screw support on locking plate fixation in proximal humeral fractures with a medial gap: a finite element analysis. Acta Orthop Traumatol Turc 2015;49:203-9. https://doi.org/10.3944/ AOTT.2015.14.0204.

20. Zanoni A, Cocco A. Masarati P Multibody dynamics analysis of the human upper body for rotorcraft-pilot interaction. Nonlinear Dyn 2020;102: 1517-39. 